\title{
Afferent loop syndrome: a case report
}

\author{
BK Basu
}

\begin{abstract}
Afferent loop syndrome (ALS) is a purely mechanical complication that infrequently occurs following construction of a gastrojejunostomy. A male patient aged $\neg 36$ years who had undergone posterior gastro-jejunostomy 9 years back (in 2006) was admitted in the Department of Surgery of Gazi Medical College Hospital through OPD with abdominal pain, nausea, anorexia, abdominal discomfort after meal and sometime bilious vomiting. All the necessary investigations including endoscopy, colonoscopy, CT scan of the abdomen and Brain, Ba-meal X-ray were repeatedly done. There was suspicious distention of afferent loop during endoscopic investigation. The main diagnostic base was the history of the disease and clinically diagnosed ALS. It is a surgical urgency. During re-laparotomy, Roux-en- $Y$ anastomosis with 'Tanner's 19' modification was done. The patient did not have any complain during follow up after 10 days of the discharge from the hospital.
\end{abstract}

Key words: Afferent loop syndrome, re-laparotomy, Roux-en-Y anastomosis.

\section{Introduction}

Afferent loop syndrome (ALS) is a purely mechanical complication that infrequently occurs following construction of a gastrojejunostomy. ${ }^{1-4}$ Creation of an anastomosis between the stomach and jejunum leaves a segment of the small bowel, most commonly consisting of duodenum and proximal jejunum, lying upstream from the gastrojejunostomy. This limb of intestine conducts bile, pancreatic juices, and other proximal intestinal secretions toward the gastrojejunostomy and is thus termed the afferent loop.

The afferent loop consists of the duodenal stump, the remainder of the duodenum, and the segment of jejunum proximal to the gastrojejunostomy. The clinically relevant portion of the loop pertaining to ALS is the jejunal portion of the afferent limb. The jejunal limb is subject to adhesion formation, internal herniation, volvulus, anastomotic obstruction, and other etiologies of ALS. A case of ALS was treated in Gazi Medical College Hospital $(\mathrm{GMCH})$ and is presented in this report.

\section{Case report}

A male patient aged 36 years from Kalaroa, Satkhira who had undergone posterior gastrojejunostomy 9 years back (in 2006) was admitted in the Department of Surgery of Gazi Medical College Hospital (GMCH) through OPD with abdominal pain, nausea, anorexia, abdominal discomfort after meal and sometime bilious vomiting. He also complained the history of irregular bowel movement. In the history of his diseases, after gastrojejunostomy in 2006 he did not feel any abdominal discomfort for 4 years. But after 4 years of the operation he again started complaining abdominal pain and nausea since 2010. The patient visited several doctors and hospitals in the different part of the country. After 6 month he had irregular vomiting after 
meal. Abdominal discomfort and pain increased day by day. In 2012, the patient was admitted in a hospital, Satkhira and then in Gopalgong, where diagnosis was done as "Sub-acute intestinal obstruction" by plain X-ray of the abdomen. Then patient went to Dhaka Apollo Hospital. Where the patient was investigated thoroughly and was undergone for $2^{\text {nd }}$ operation for sub-acute intestinal obstruction. But after the $2^{\text {nd }}$ operation the symptom did not relieve. In 2014, the patient was admitted in Bangabandhu Sheikh Mujib Medical University (BSMMU), where he was thoroughly investigated again (CT scan of the abdomen, video-endoscopy, colonoscopy, USG, X-ray of the abdomen, etc.), but no pathology was detected and treated conservatively. In 2014, the patient visited different hospitals like Popular Hospital, Dhaka, Medinova, Dhaka, and various investigations were done repeatedly. Like gastrography, Ba-meal and Ba-enema X-ray, CT scan abdomen, endoscopy, videocolonoscopy, etc. But no pathology was detected and in January 2015 the patient was admitted repeatedly in BSMMU where all the investigation were normal. But by the X-ray Ba-enema swallow through terminal ileal stricture was diagnosed and was advised for operative treatment. The patient was admitted in $\mathrm{GMCH}$ on 18 March 2015 as a diagnosed case of ileal stricture for operative treatment. After proper preoperative preparation and correction of fluid electrolyte imbalance and resuscitation the patent under went for operation on 20 March 2015. Laparotomy, showed that the terminal ileum was narrowed about 9 inch. No fibrosis was detected. Resection of 1.5 feet terminal ileum with cecum was done followed by end to end ileo-ascending anastomosis. The patient recovered well and started oral feeding from $7^{\text {th }}$ POD on 27 April 2015, when the hemodynamic, liver function, kidney function and serum electrolyte were within normal limit. But, unfortunately from the next day of oral feeding, the previous symptoms like abdominal pain, abdominal discomfort, bilious vomiting, etc were started. All the necessary investigations including endoscopy, colonoscopy, CT scan of the abdomen and Brain, Ba-meal X-ray were repeatedly done. There was suspicious distention of afferent loop during endoscopic investigation. But the main diagnostic base was the history of the disease and clinically diagnosed as ALS. The medical board decided for re-laparotomy. Re-laparotomy was done on 9 April 2015. Re-laparotomy showed extensive adhesions was on the site of previous gastro-jejunostomy. Hugely distended afferent loop was found after release of adhesion which was about $40 \mathrm{~cm}$ in length. Roux-en-Y anastomosis with 'Tanner's 19' modification was done. The patient recovered well and started taking food orally from $7^{\text {th }}$ POD of $2^{\text {nd }}$ operation. The symptoms were relived. The operative wound was infected and secondary closer was done on 30 April 2015. The patient was discharged from the hospital with full recovery on 9 May 2015. The patient came for further follow up after 10 days of the discharge from the hospital and did not have any complain.

\section{Discussion}

ALS is an intermittent partial or complete mechanical obstruction of the afferent limb of a gastro-jejunostomy. It can be seen after partial gastrectomy, Billroth II gastrojejunostomy, gastric bypass, Roux-en-Y gastric bypass and pancreaticoduodenectomy. ${ }^{1-5}$

\section{History}

In 1942, McNealy first described acute ALS as a cause of early postoperative duodenal stump leakage. Lake is credited with recognizing the chronic form in 1948. Roux and coworkers used the term afferent loop syndrome in $1950 .{ }^{6}$ The first detailed in the English literature about the etiology, clinical presentation and treatment of ALS was contributed by Wells and Welbourn in $1951 .{ }^{7}$

\section{Epidemiology}

ALS is an uncommon postoperative complication and different studies has estimated that it occurs from $1 \%$ to $13 \%$ of postgastrectomy (Billroth II) or postpacreaticoduodenectomy patients and the incidence of this complication decreased dramatically during the final quarter of the 20th century as elective gastric surgery for complications of peptic ulcer disease underwent a logarithmic decline..$^{8,9}$

\section{Causes}

The possible causes may be an improperly made anastomosis, twisting or kinking of the afferent loop, trapping of the afferent loop secondary to scar tissue in an area near the surgery, scarring from ulceration at the site where the afferent loop joins the stomach, 
cancer that recurs and blocks the afferent loop, etc. Bushkin and Woodward reported an equal incidence of ALS in patients with short, retrocolic afferent limbs. ${ }^{10}$ However, according to Eagon and coworkers, most authors opine that longer, redundant, and antecolic afferent limbs are more prone to kinking, volvulus, and entrapment by adhesions. ${ }^{11}$

\section{Pathophysiology}

An afferent loop is composed of the duodenal stump, the remainder of the duodenum, and the segment of jejunum located proximal to a Billroth II type gastro-jejunostomy. ALS is caused by complete or partial mechanical obstruction at the gastrojejunostomy or at a point along the jejunal portion of the afferent loop.

Passage of food and gastric secretions through the gastrojejunostomy and into the efferent loop triggers release of secretin and cholecystokinin. Increase in secretion of bile, pancreatic enzymes, pancreatic bicarbonate and water into the afferent loop. Symptoms associated with ALS are caused by increased intraluminal pressure and distention. ${ }^{12}$ It may be the etiological causes of postoperative obstructive jaundice, ascending cholangitis, and pancreatitis. It can lead to ischemia and gangrene of afferent loop with subsequent perforation and peritonitis.

Secondarily, prolonged stasis and pooling of secretions with partial obstruction facilitate bacterial overgrowth in the afferent loop. ${ }^{13}$ Bacteria deconjugate bile acids, which can lead to steatorrhea, malnutrition, and vitamin $\mathrm{B}_{12}$ deficiency leading to megaloblastic anemia. The severity at presentation mainly depends on the degree and duration of obstruction.

\section{Common signs and symptoms}

If there is only partial blockage, the symptoms may be some burping (as mouthfuls of bile juice), usually an hour or so after eating. ${ }^{14}$ Later, there is a felling of fullness in the stomach and maybe some pain in the upper part of the abdomen, which is followed by vomiting. The stools become bulky and gray, because there is no bile or pancreas juice in them. Even later, the liver and pancreas become affected.

\section{Diagnostic procedures}

X-ray Ba-meal swallow though (Fig. 1), plain X-ray of the abdomen (Fig. 2), gastrography (Fig. 3), video/ capsule/ double balloon endoscopy (Fig. 4), CT scan of the abdomen (Fig. 5), MRI of the abdomen (Fig. 6), etc are used to diagnose ALS.

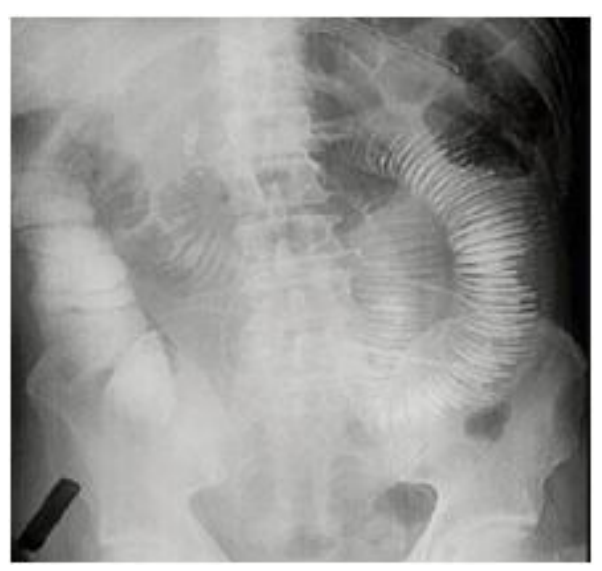

Fig. 1. X-ray Ba-meal swallow though.
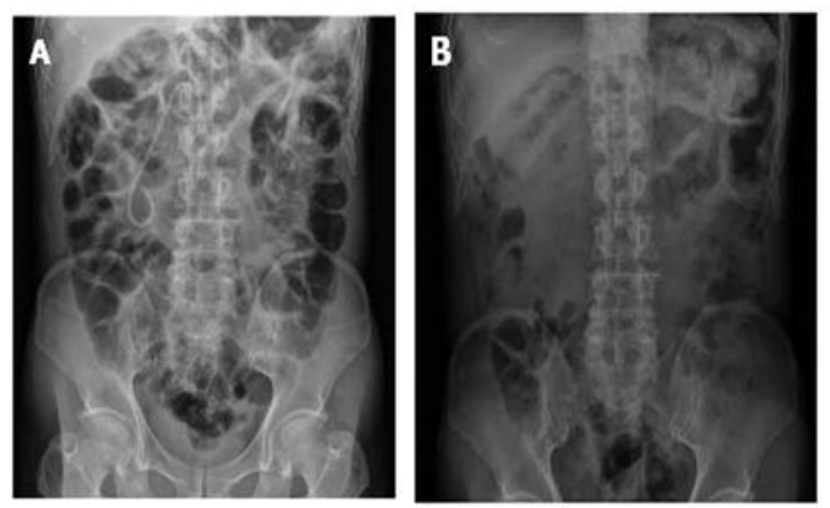

Fig. 2. Plain X-ray of the abdomen.

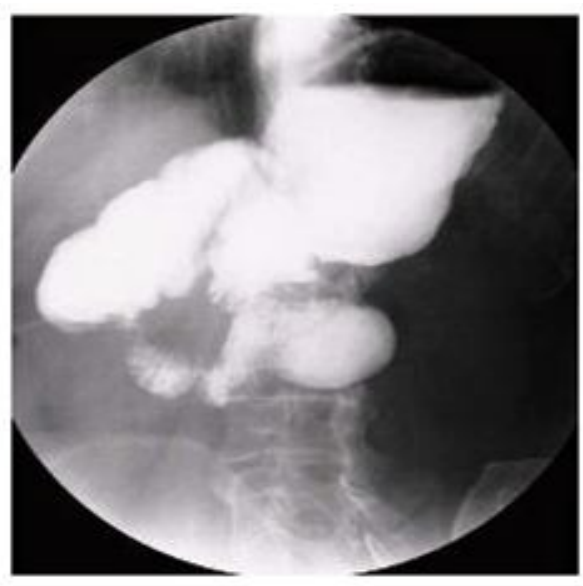

Fig. 3. Gastrography. 

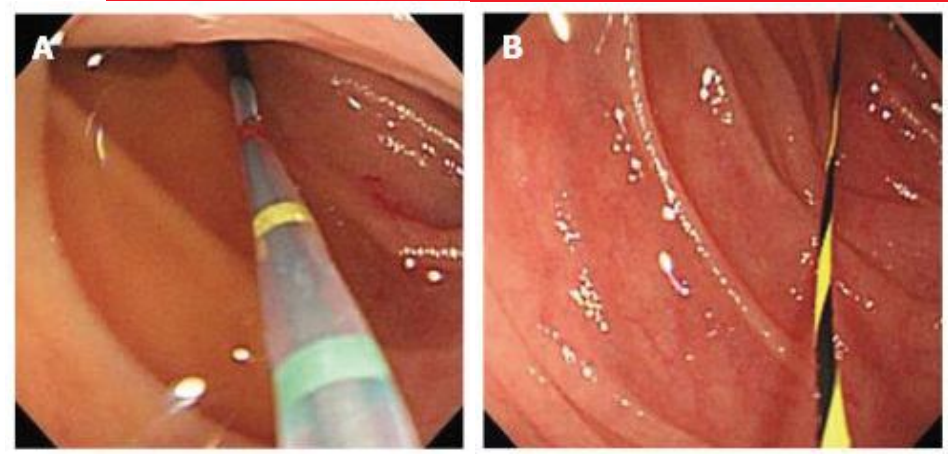

Fig. 4. Video/ capsule/ double balloon endoscopy.
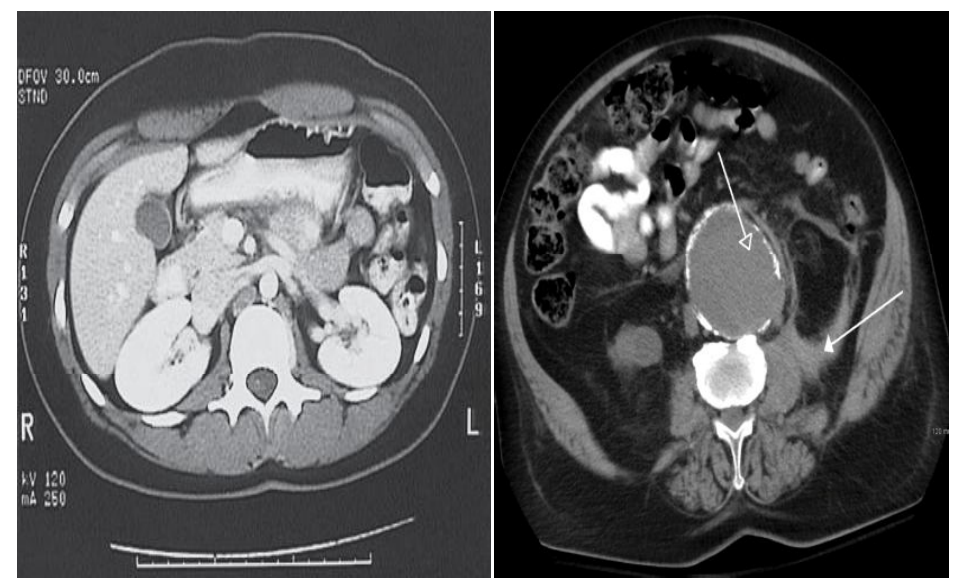

Fig. 5. CT scan of the abdomen.

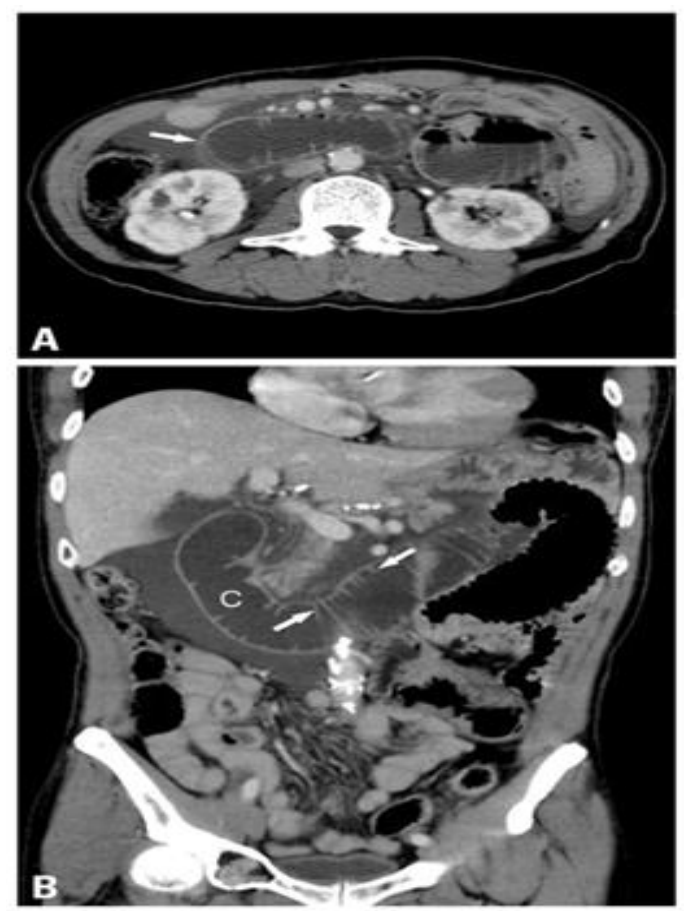

Fig. 6. MRI of the abdomen.
Treatment

It is a surgical urgency. ${ }^{15-18}$

\section{Conclusion}

In conclusion, afferent loop syndrome following after a gastro-jejunostomy can be diagnosed by meticulous history taking, physical examination and endoscopic method modalities. In our opinion 'Roux-en-Y anastomosis' with the 'Tenner's 19' modification should be considered as the best method of treatment of this disease.

\section{References}

1. Tsutsui S, Kitamura M, Shirabe K, Baba $\mathrm{H}$, Sugimachi K. Afferent loop syndrome due to scarring of a stomal ulcer following a Billroth II gastrectomy. Endoscopy 1995;27(5):410.

2. Carbognin G, Biasiutti C, El-Khaldi M, Ceratti S, Procacci C. Afferent loop syndrome presenting as enterolith after Billroth II subtotal gastrectomy: a case report. Abdom Imaging 2000;25(2):12931.

3. Kim HJ, Moon JH, Choi HJ, et al. Endoscopic removal of an enterolith causing afferent loop syndrome using electrohydraulic lithotripsy. Dig Endosc 2010;22(3):220-2.

4. Hui MS, Perng HL, Choi WM, Chem LK, Yang KC, Chen TJ. Afferent loop syndrome complicated by a duodenal phytobezoar after Billroth-II subtotal gastrectomy. Am J Gastroenterol 1997;92(9):1550-2.

5. Ballas KD, Rafailidis SE, Konstantinidis $H D$, et al. Acute afferent loop syndrome: a true emergency. A case report. Acta Chir Belg 2009;109(1):101-3.

6. Roux G, Pedoussaut R, Marchal G. [Afferent loop syndrome of gastrectomized subjects][French]. Lyon Chir 1950;45(7):773-80.

7. Wells C, Welbourn R. Post-gastrectomy syndromes: a study in applied physiology. Br Med J 1951;17:546-54.

8. Burkhalter $\mathrm{E}$. Incidence of gastrectomy in United States army hospitals worldwide from 1975 to 1985 . Am J Gastroenterol 1988;83(11):1231-4.

9. Paimela $\mathrm{H}$, Tuompo PK, Perakyl T, Saario I, Hockerstedt K, Kivilaakso E. Peptic ulcer surgery during the H2-receptor antagonist era: a population-based epidemiological study of ulcer surgery in Helsinki from 1972 to 
1987. Br J Surg 1991;78(1):28-31.

10. Bushkin FL, Woodward ER. The afferent loop syndrome. Major Probl Clin Surg 1976;20:34-48.

11. Eagon JC, Miedema BW, Kelly KA. Postgastrectomy syndromes. Surg Clin North Am 1992;72(2):445-65.

12. Locke GR, Alexander GL, Sarr MG. Obstructive jaundice: an unusual presentation of afferent loop obstruction. Am J Gastroenterol 1994;89(6):942-4.

13. Rana SV, Bhardwaj SB. Small intestinal bacterial overgrowth. Scand J Gastroenterol 2008;43(9):1030-7.

14. Matsusue S, Kashihara S, Takeda H, Koizumi S. Three cases of afferent loop obstruction-the role of ultrasonography in the diagnosis. Jpn J Surg 1988;18(6):709-13.
15. Kim HJ, Kim JW, Kim KH, et al. [A case of afferent loop syndrome treated by endoscopic drainage procedure using nasogastric tube] [Korean]. Korean J Gastroenterol 2007;49(3):173-6.

16. Borrelli D, Borrelli A, Presenti L, Bergamini C, Basili G. [Surgical approach of the functional post-partial gastrectomy syndromes] [Italian]. Ann Ital Chir 2007;78(1):3-10.

17. Vettoretto N, Pettinato G, Romessis M, Bravo AF, Barozzi G, Giovanetti M. Laparoscopy in afferent loop obstruction presenting as acute pancreatitis. JSLS 2006;10(2):270-4.

18. Aimoto T, Uchida E, Nakamura $Y$, et al. Malignant afferent loop obstruction following pancreaticoduodenectomy: report of two cases. J Nippon Med Sch 2006;73(4):226-30.

\section{Suggestion for citation of the above:}

Basu BK. Afferent loop syndrome: a case report. Mediscope 2016;3(2):39-43. 